\title{
Türk ahşap konut örneği Nemlioğlu Konağı'nın mekanik direnç özelliklerinin tahribatsız test teknikleriyle incelenmesi
}

\section{$\ddot{O} z$}

\author{
Engin Derya Gezer ${ }^{1 * D}$, Cenk Demirkır ${ }^{1}$ (D), Turgay Özdemir ${ }^{1}$ (D)
}

Türkiye'de ahşap taşıyıcı sisteme sahip yapılar yaklaşık 40 yıl öncesine kadar yaygın bir şekilde geleneksel olarak inşa edilmişlerdir. Yangınlar, çürüme, malzeme darlığı, ormanların azalacağı düşüncesi ve hızlı kentleşmeye bağlı olarak betonarme yapıların artması ahşap yapılardan vazgeçilmesine neden olmuştur. Oysaki ABD, Kanada, Japonya ve Avustralya gibi deprem tehdidi altındaki ülkeler, gelişen teknolojik imkanlardan da yararlanarak ahşap yapı inşasına devam etmişlerdir. Ahşabın Türk konut tarihindeki önemi ve ahşabın kullanıldığı halen ayakta kalan örnek yapıların gösterdiği performansın tespit edilmesi, ahşap yapı kültürünün tekrardan canlandırılması noktasında önemli olarak görülmektedir. Bu çalışmanın amacı, Karadeniz Bölgesi Trabzon ilinde 1892 yılında ahşap malzeme ile inşa edilmiş Nemlioğlu konağının ahşap malzemelerinin hasarlı ve hasarsız test yöntemleri ile test edilerek performanslarının değerlendirilmesidir. Böylelikle halen ayakta kalan ahşap konağın ahşap elemanlarının mekanik performansları üzerinden Türk ahşap konut sistemi ile ilgili bilimsel verilere ulaşılması hedeflenmektedir. Bu amaçla Nemlioğlu Konağı'nın taşıyıcı kısımlarının belirli bölgelerinden örnekler alınarak eğilme direnci ve elastikiyet modülü testleri yapılmıştır. Ayrıca hasarsız test cihazlarıyla binanın taşıyıcı elemanlarındaki tahribat, kusurlar ve direnç özellikleri belirlenmeye çalışılmıştır. Elde edilen sonuçlar incelendiğinde söz konusu konaktaki ahşap elemanların büyük bir kısmının hala taşıyıcı özelliğini koruduğu ve standartlarda belirlenen asgari mekanik direnç özelliklerini sağladıkları belirlenmiştir.

Anahtar kelimeler: Türk Ahşap Konutları, Nemlioğlu Konağı, Hasarsız Test Yöntemleri

\section{Investigation of Turkish wooden housing case Nemlioğlu mansion in terms of mechanical resistance properties by non-destructive test methods}

\begin{abstract}
In Turkey, structures with wooden carrier system were traditionally built until about 40 years ago. The increase in reinforced concrete structures due to fires, decay, material shortages, the thought that forests will decrease and rapid urbanization caused wooden structures to be abandoned. However, countries under the threat of earthquakes such as the USA, Canada, Japan and Australia continued to build wooden structures by taking advantage of the developing technological opportunities. The importance of wood in Turkish housing history and the determination of the performance of exemplary structures that still use wood are seen as important in terms of reviving the wooden building culture. The aim of this study was to evaluate the performance of the wooden materials of Nemlioğlu mansion, which was built with wooden materials in 1892 in the Black Sea region of Trabzon province, by testing the wooden materials with destructive and non-destructive test methods. Thus, it was aimed to reach scientific data about the Turkish wooden housing system through the mechanical performances of the wooden elements of the wooden mansion that was still standing. For this purpose, samples were taken from certain parts of the bearing parts of Nemlioğlu Mansion, and bending strength and modulus of elasticity tests were carried out. In addition, the damage, defects and resistance properties of the building's bearing elements were tried to be determined with nondestructive test devices. When the results obtained were examined, it was determined that most of the wooden elements in the mansion in question still maintain their load-bearing properties and provided the minimum mechanical resistance properties specified in the standards.
\end{abstract}

Keywords: Turkish Wooden Housing, Nemlioğlu Mansion, Nondestructive Tests

Makale tarihçesi: Geliș:05.10.2021, Kabül:13.12.2021, Yayınlanma:27.12.2021, *e-posta: engin_gezer@yahoo.com, ${ }^{1}$ Karadeniz Teknik Üniversitesi, Orman Fakültesi, Orman Endüstri Mühendisliği Bölümü, Trabzon, Türkiye

Atıf: Gezer, E.D., Demirkır, C., Özdemir, T. (2021), Türk ahşap konut örneği Nemlioğlu Konağı'nın mekanik direnç özellikleri açısından incelenmesi, Mobilya ve Ahşap Malzeme Araştırmaları Dergisi, 4(2), 138-144,

DOI: $10.33725 / \operatorname{mamad} .1004967$ 


\section{Giriş}

Türkiye'de ahşap taşıyıcı sisteme sahip yapılar yaklaşık 40 yıl öncesine kadar yaygın bir şekilde geleneksel olarak inşa edilmişlerdir. Yangınlar, çürüme, malzeme darlığı, ormanların azalacağı düşüncesi ve hızlı kentleşmeye bağlı olarak betonarme yapıların artması ahşap yapılardan vazgeçilmesine neden olmuştur. Oysaki ABD, Kanada, Japonya ve Avustralya gibi deprem tehdidi altındaki ülkeler, gelişen teknolojik imkanlardan da yararlanarak ahşap yapı inşasına devam etmişlerdir. 1999 yılı depremi sonrasında betonarme yapılarda izlenen ağır hasarlar, geleneksel ahşap karkas yapıların depremi hasarsız ya da az hasarlı aşmaları, ahşap yapılarla ilgili Türkiye'deki yaygın anlayışların sorgulanmasını gündeme getirmiştir. Türkiye Ulusal Deprem Stratejisi ve Eylem Planına (Anonim, 2012) göre depreme dayanıklı binaların tasarım, malzeme ve standartlarını içeren çalışmalar destekleneceği ifade edilmiştir (Demirkır ve ark., 2013). Bu nedenle ahşabın Türk konut tarihindeki önemi ve ahşabın kullanıldığı halen ayakta kalan örnek yapıların gösterdiği performansın tespit edilmesi, ahşap yapı kültürünün tekrardan canlandırılması noktasında önemli olarak görülmektedir. Ahşap; birçok bölgesel ve değişik malzemeye dayalı yerel konut gelenekleri içinde Türklerin tercih ettikleri ana konut malzemesi olmuştur. Karadeniz Bölgesinde de bu yapı örneklerinden bazılarına rastlamak mümkündür.

Geçmişten günümüze sayısız medeniyet ve kültüre ev sahipliği yapmış olan Karadeniz Bölgesi, zengin kültür mirası, tarihi, estetik arkeolojik değerleriyle pek çok tarihi geleneği bir arada yaşatmaktadır. Kültür ve Turizm Bakanlığı'nın verilerine göre 2014 Haziran ayı sonu itibariyle Doğu Karadeniz Bölgesindeki 6 ilde (Ordu, Giresun, Trabzon, Gümüşhane, Rize, Artvin) tescilli taşınmaz kültür varlıklarının sayısının 3845 olduğu bildirilmektedir (URL 1). Güçlü ekonomilerin kontrolü altına giren ve tüm yaşam ifadelerinin tek düzeyde birleşmesini hedef alan küreselleşme kavramının, kültürel mirasın zaman içerisinde yok olmasında etkin rol oynayacağı düşünülmektedir. Bu hususta değerlerimize sahip çıkmak ve bu mirasın sağlıklı bir şekilde nesiller boyu varlıklarını sürdürebilmeleri bakımından ahşap yapıları koruma ve onarım çalışmalarının önemi artmaktadır. Tarihi ve ahşap yapıların öznel dokusunu bozmadan onarılması ve yaşatılması amacıyla ağaç malzemenin tahribatlı ya da kusurlu bölgelerinin uygun müdahale yöntemleriyle giderilmesi gerekmektedir. Günümüzde ahşap yapıların restorasyon çalışmaları genellikle mimarların ya da inşaat mühendislerinin tekelinde yürütülmektedir. Ağaç malzeme hakkında teknik bilgiye sahip olan orman endüstri mühendisliğinin bilgisinden faydalanılmadı̆̆ görülmekte ve sadece mimari açıdan ele alınmaktadır. Bu nedenle, bu zamana kadar tarihi ahşap binalar üzerine yapılan çalışmaların büyük bir çoğunluğu mimari ve estetik özellikleri açısından ele alınmıştır. Bu çalışma kapsamında orijinal halin korunması amacıyla ağaç malzemedeki kusur ve tahribatların tespiti ile bu zamana kadarki yürütülen yaklaşımlardan farklı bir uzmanlık alanı ve teknik bakış açısı ile ele alınmıştır.

Bu çalışmanın amacı, Karadeniz Bölgesi, Trabzon ilinde 1892 yılında ahşap malzeme ile inşa edilmiş Nemlioğlu Konağı'nın ahşap malzemelerinin hasarlı ve hasarsız test yöntemleri ile test edilerek performanslarının değerlendirilmesidir. Böylelikle halen ayakta kalan ahşap konağın ahşap elemanlarının mekanik performansları üzerinden Türk ahşap konut sistemi ile ilgili bilimsel verilere ulaşılması hedeflenmektedir.

\section{Materyal ve Metot}

\subsection{Materyal}

Nemlioğlu Konağı'nın taşıyıcı kısımlarının belirli bölgelerinden örnekler alınarak eğilme direnci ve elastikiyet modülü testleri TS 2474 ve TS 2478 standartlarına göre yapılmıştır. 
Nemlioğlu Konağı'nın taşıyıcı kolon ve kirişlerinin sarıçam odunundan yapıldı̆̆ tespit edilmişstir.

\subsection{Metot}

\subsubsection{Hasarlı Testler}

Nemlioğlu Konağı'ndaki taşıyıcı ahşap kısımlarından alınan örnekler laboratuvara getirilip, ilgili standartlara göre kesilip hazırlandıktan sonra klima odasında denge rutubetine ulaşıncaya kadar bekletilmiştir. Söz konusu örneklerde aşağıdaki testler gerçekleştirilerek direnç özellikleri belirlenmiştir.

\section{Ĕgilme Direnci}

Örnekler, sıcaklığ $20 \pm 2^{\circ} \mathrm{C}$ ve bağıl nemi $\% 65 \pm 5$ olan iklimlendirme odasında değişmez ağırlığa ulaşıncaya kadar bekletilmiştir. Örneklerin genişlik ve kalınlıkları dijital mikrometre ile belirlenmiştir. Eğilme direnci;

$$
\sigma_{\mathrm{e}}=(3 / 2) \times\left(\text { Fmax } \times \mathrm{Ls} / \mathrm{b} \times \mathrm{d}^{2}\right)\left(\mathrm{N} / \mathrm{mm}^{2}\right)
$$

eşitliğinden hesaplanmıştır (TS 2474). Burada;

Fmax: Kırılma anındaki maksimum kuvvet (N)

Ls: Dayanak noktaları arasındaki açıklık $(\mathrm{mm})$

d: Örnek kalınlığ 1 (mm)

b: Örnek genişliği $(\mathrm{mm})$

\section{Ĕ̆ilmede Elastikiyet Modülü}

Örnekler, sıcaklığ $20 \pm 2^{\circ} \mathrm{C}$ ve bağ 1 nemi $\% 65 \pm 5$ olan iklimlendirme odasında değişmez ağırlığa ulaşıncaya kadar bekletilmiştir. Eğilmede elastikiyet modülünün (E) belirlenmesinde;

$$
\mathrm{E}=\mathrm{F}_{\mathrm{L} \mathrm{Ls}} \mathrm{Ls}^{3} / 4 \mathrm{x} \Delta \mathrm{e} \mathrm{b} \times \mathrm{d}^{2}\left(\mathrm{~N} / \mathrm{mm}^{2}\right)
$$

eşitliği kullanılmıştır (TS 2478 ). Burada;

$\Delta \mathrm{e}$ : Eğilme miktarı (sehim) (mm)

F: Deformasyon sağlayan kuvvet $(\mathrm{N})$

Ls: Dayanak noktaları arasındaki açıklık $(\mathrm{mm})$

d: Örnek kalınlığg $(\mathrm{mm})$

b: Örnek genişliği (mm)

\subsubsection{Hasarsiz testler}

\section{Resistograf}

Rezistograf son zamanlarda geliştirilen bir delme cihazıdır. Bu cihaz (IML-RESI F 300S) ahşap elemanlarda (ağaçlar, direkler, kirişler vb.) kullanılmak üzere tasarlanmıştır (Seavey ve Larson, 2002). Bu teknik yerel kusur bölgelerini incelemek, belirlemek ve boyutunu saptamak açısından etkili bir cihazdır ve bu yerel kusur bölgeleri gelişen ağaçta olabilir. Bu cihazla gözle görülebilir durumdaki çatlaklar, şiddetli çürüme alanları, oyuklar, ağaç halka yapıları ve bununla birlikte geriye kalan çeper kalınlığı tespit edilebilir (Lee vd., 2003). Rezistograf cihazının çalışma ilkesi; milin (ucun-iğnenin) odun içerisinde ilerleme hızının gelişmiş elektronik ve mekanik sensörler sayesinde grafiğe aktarılmasıdır. Bir başka ifade ile 
odunun özgül ağırlığının yüksek olduğu kısımlarda milin ilerlemesi yavaş olacağından yüksek dirence maruz kalmakta ve yüksek pik vermektedir. Çürüklük zonlarında ve boşluk bölgelerinde odunun özgül ağırlığı düşük olduğundan milin ilerlemesi ve karşılaşmış olduğu direnç daha düşük olmaktadır ve daha düşük pik vermektedir (Şekil 1) (Gezer ve ark., 2015).

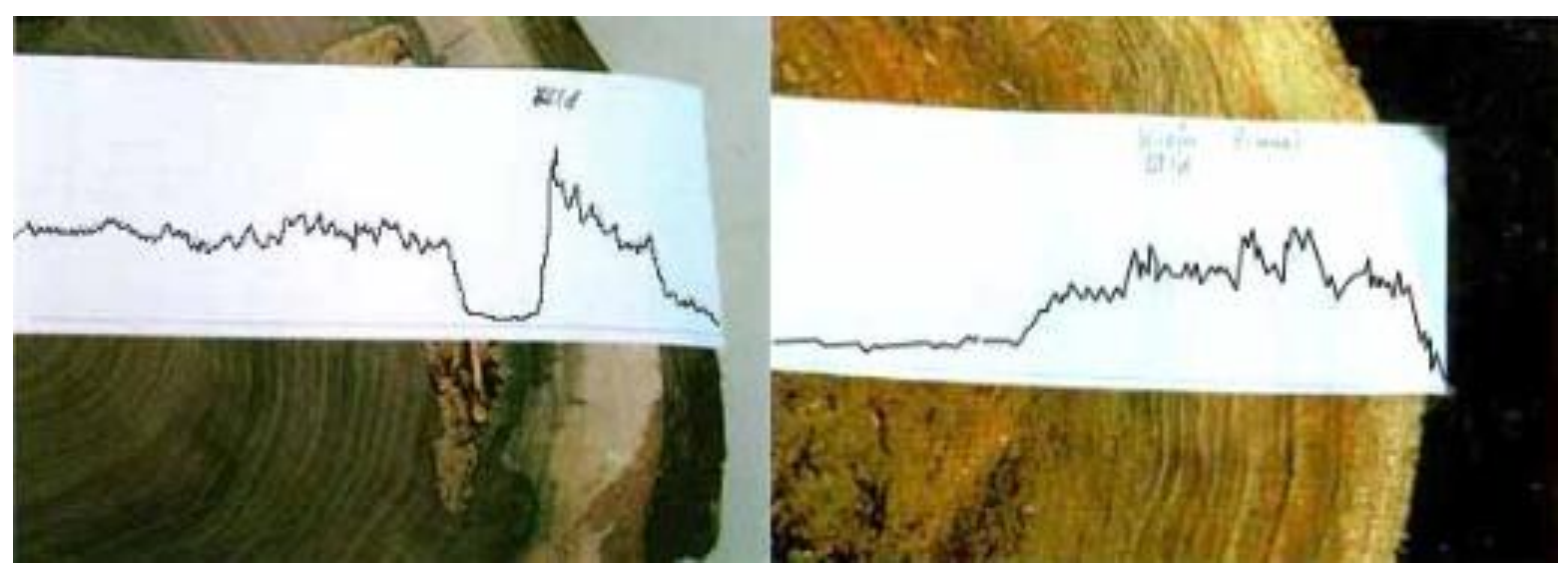

Şekil 1. Resistograph cihazı ile ağaç malzemelerin iç kısımlarındaki çürüklük ve boşluk alanlarının belirlenmesi

\section{Vida çekme direnci}

Hasarsız olarak ahşap yapılardaki taşıyıcı kolon ve kirişlerde vida çekme direncini belirlemek amacıyla FAKOPP firması tarafından geliştirilen test cihazı kullanılmıştır (Şekil 2) (Gezer ve ark., 2018). Vida çekme direnci, malzemenin direncinin, yoğunluğunun ve makaslama modülünün göstergesidir. Bu cihaz ile elde edilen vida çekme direnci verileri sayesinde malzemenin makaslama modülü ve eğilme direnci de hesaplanabilmektedir. Nemlioğlu Konağında incelenen taşıyıcı kolon ve kirişlerde en az 5'er ölçüm yapılarak vida çekme ve makaslama modülü değerleri belirlenmiştir. Makaslama modülü aşağıda verilen formül sayesinde hesaplanmıştır (URL-1).

$\mathrm{G}=224 \times \mathrm{F}_{\mathrm{Vida}}+210$

Burada; G makaslama modülünü (MPa), $\mathrm{F}_{\text {Vida }}$ ise vida çekme direncidir (MPa).
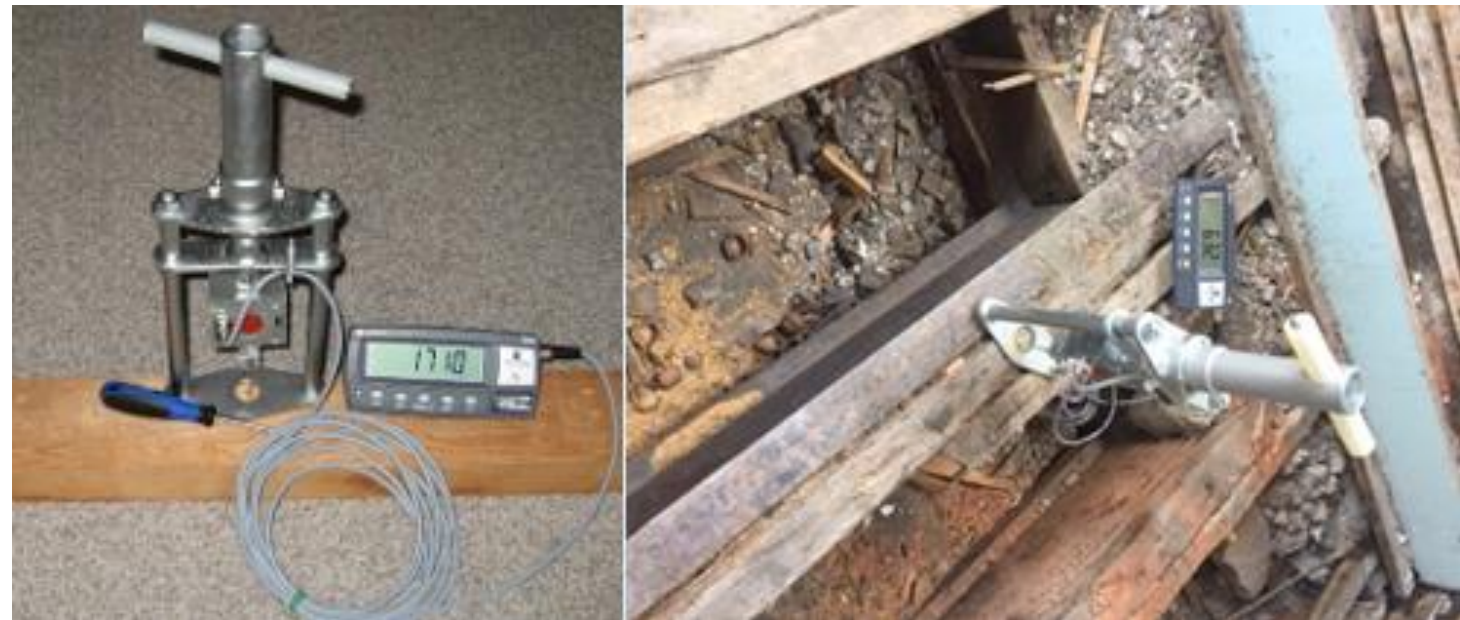

Şekil 2. Vida tutma/çekme direncinin belirlenmesi 


\section{Bulgular ve Tartışma}

Nemlioğlu Konağı'ndaki taşıyıcı kirişlerden alınan örneklerde tahribatlı testler sonucunda elde edilen eğilme direnci ve eğilmede elastikiyet modülü değerleri Tablo 1' de verilmiştir.

Tablo 1. Eğilme direnci ve eğilmede elastikiyet modülü değerleri

\begin{tabular}{ccc}
\hline Taşıyıcı Kiriş & $\begin{array}{c}\text { Eğilme Direnci } \\
\left(\mathbf{N} / \mathbf{m m}^{2}\right)\end{array}$ & $\begin{array}{c}\text { Elastikiyet Modülü } \\
\left(\mathbf{N} / \mathbf{m m}^{\mathbf{2}}\right)\end{array}$ \\
\hline No 1 & 60.36 & 3780.00 \\
No 2 & 60.67 & 3558.11 \\
No 3 & 69.26 & 4872.32 \\
\hline Ortalama & 63.43 & 4070.14 \\
\hline
\end{tabular}

Elde edilen bulgular EN 338 (2009) yapısal ahşap sinıflandırması standardına göre incelendiğinde, iğne yapraklı ağaçlar için mekanik özellikler açısından C18 sınıfı ve üzerindeki sınıfa giren ahşap malzemelerin yapısal kullanım için uygun olduğu belirtilmektedir. Testleri yapılan örnekler için eğilme direnci değerleri EN 338 standardında belirtilen sınır değerleri karşıladığı tespit edilmiştir.

Nemlioğlu konağındaki taşıyıcı kirişlerde rezistograf cihazıyla hasarsız olarak gerçekleştirilen incelemeler ait rezistograf çıktılarından bazıları Şekil 3' te verilmiştir.
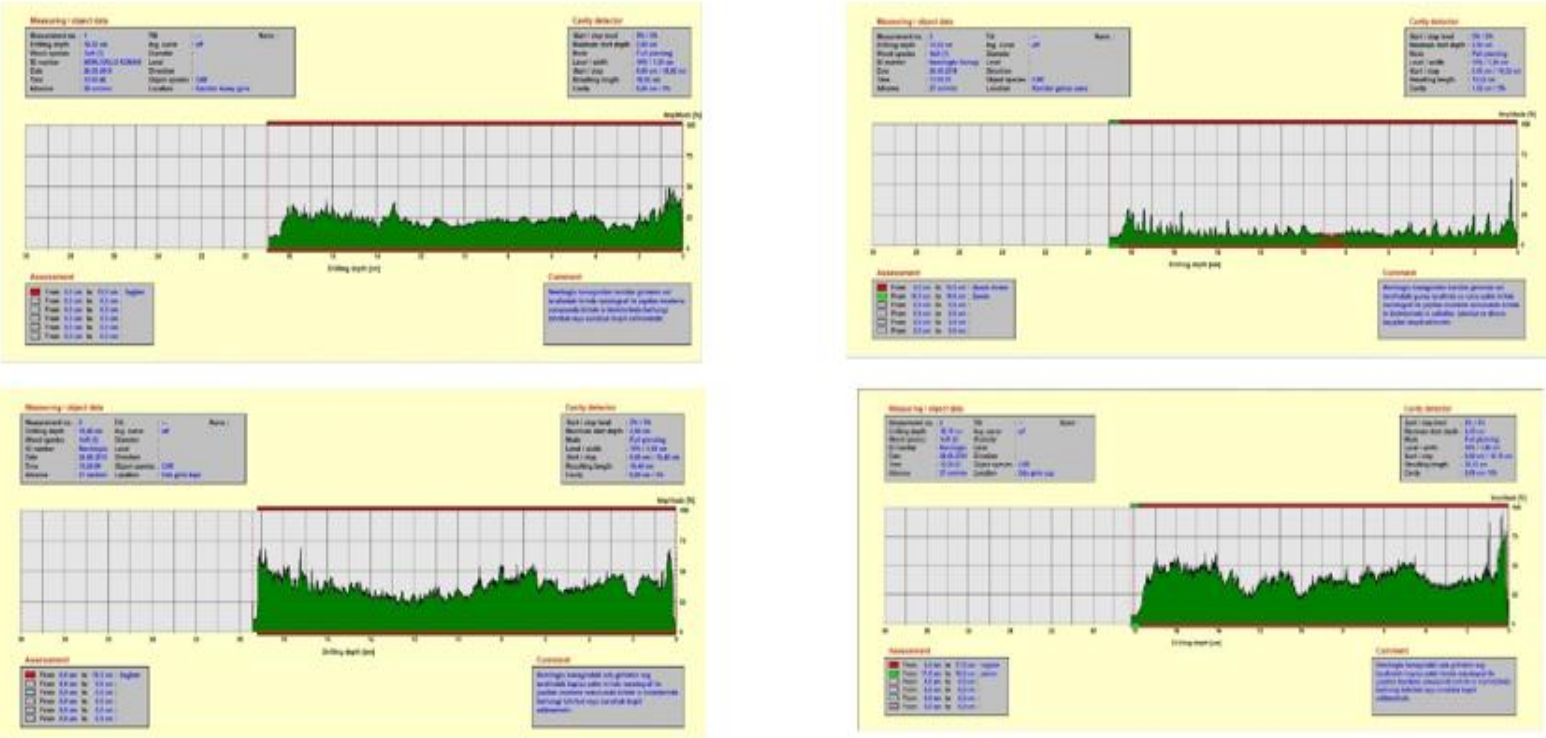

Şekil 3. Nemlioğlu Konağı'nda incelenen taşıyıcı kirişlere ait rezistograf çıktıları

Nemlioğlu Konağı'nda rezistograf ile yapılan incelemeler sonucunda taşıyıcı kirişlerin \%90'ının sağlam ve yüksek dirence sahip olduğu belirlenmiştir. Tahribat ve kusurlu olduğu tespit edilen taşıyıcı kirişler daha önceden metal aksamlarla güçlendirilmiştir.

Nemlioğlu Konağı'ndaki taşıyıcı kirişlerde vida tutma cihazıyla hasarsız olarak gerçekleştirilen ölçümler sonucunda elde edilen vida tutma direnci, eğilme direnci ve makaslama modülüne ait bulgular Tablo 2'de verilmiştir. 
Tablo 2. Vida çekme direnci, eğilme direnci, makaslama modülü değerleri

\begin{tabular}{ccccccc}
\hline Taşıyıcı Kiriş & \multicolumn{2}{c}{$\begin{array}{c}\text { Vida Çekme } \\
\text { Direnci }(\mathbf{k N})\end{array}$} & \multicolumn{2}{c}{$\begin{array}{c}\text { Eğilme Direnci } \\
\left(\mathbf{N} / \mathbf{m m}^{2}\right)\end{array}$} & \multicolumn{2}{c}{$\begin{array}{c}\text { Makaslama } \\
\text { Modülü }(\mathbf{M P a})\end{array}$} \\
\hline & Ort. & Std. & Ort. & Std. & Ort. & Std. \\
No 1 & 1.77 & 0.03 & 58.93 & 1.10 & 605.81 & 7.29 \\
No 2 & 1.55 & 0.22 & 57.54 & 7.53 & 556.98 & 49.74 \\
No 3 & 2.15 & 0.12 & 71.93 & 4.03 & 691.60 & 26.61 \\
No 4 & 1.40 & 0.04 & 46.48 & 1.40 & 523.60 & 9.50 \\
\hline Ortalama & 1.72 & 0.10 & 58.72 & 3.52 & 594.50 & 23.29
\end{tabular}

Nemlioğlu Konağı'nda hasarsız vida çekme direnci test cihazıyla yapılan incelemeler sonucunda taşıyıcı kirişlerin vida çekme, eğilme ve makaslama direnci değerlerinin standartlarda belirtilen asgari değerleri karşıladığı tespit edilmiştir.

Hasarsız yöntem ile belirlenen eğilme direnci değerlerinin tahribatlı yöntemle belirlenen değerlerle uyum içerisinde olduğu görülmüştür. Bilindiği üzere, tarihi ahşap binaların restorasyonunda mümkün olduğunca yapının orijinal özelliklerini koruyarak sadece hasarlı/kusurlu bölgelerin çıkartılıp yenilenmesi gerekmektedir. Tahribatlı yöntemlerle ahşap taşıyıcıların direnç özelliklerinin belirlenebilmesi için yapıdan çok sayıda örnek kesilmesi/alınması gerektiğinden yapıya oldukça fazla zarar verilmesine ve yapının kendine özgü orijinal halinin bozulmasına neden olmaktadır. Bu çalışmada elde edilen bulgular ışığında, tarihi ahşap yapılardaki taşıyıcı elemanların direnç özelliklerinin yapıya hasar verilmeden hasarsız test yöntemleriyle doğru bir şekilde belirlenmesinin mümkün olabileceğini göstermiştir. Dolayısıyla ülkemizde gerek tescilli, gerekse tescilsiz tarihi ahşap yapıların restorasyonunda hasarlı/tahribatlı/düşük dirençli ahşap elemanların belirlenmesinde hasarsız test yöntemlerinin kullanılması önerilmeli veya zorunlu hale getirilmedir.

\section{Sonuçlar ve Öneriler}

Yapılan çalışma sonunda elde edilen verilere göre şu sonuçlar söylenebilir;

- Nemlioğlu Konağı'nda rzistograf ile yapılan incelemeler sonucunda taşıyıcı kirişlerin \%90'ının sağlam ve yüksek dirence sahip olduğu belirlenmiştir.

- Nemlioğlu Konağı'nda hasarsız vida çekme direnci test cihazıyla yapılan incelemeler sonucunda taşıyıcı kirişlerin vida çekme, eğilme ve makaslama modülü standartlarda belirtilen asgari değerleri karşılamaktadır.

- Hasarlı test sonuçları EN 338 (2009) yapısal ahşap sınıflandırması standardına göre incelendiğinde, iğne yapraklı ağaçlar için mekanik özellikler açısından C18 sınıfı ve üzerindeki sınıfa giren ahşap malzemelerin yapısal kullanım için uygun olduğu belirtilmektedir. Testleri yapılan örnekler için eğilme direnci değerlerinin EN 338 standardında belirtilen sınır değerleri karşıladığı ve hasarsız test yöntemi sonuçları ile uyumlu olduğu belirlenmiştir.

\section{Teșekkür r}

$\mathrm{Bu}$ çalışma, Kahramanmaraş Sütçü İmam Üniversitesi, Orman Fakültesi tarafından düzenlenen III. International Mediterranean Forest and Environment Symposium adlı sempozyumda sözlü bildiri olarak kabul edilmiş ve sunulmuştur. 


\section{Yazar Katkıları}

Engin Derya Gezer: Hasarsız testlerin gerçekleştirilmesi, verilerin elde edilmesi, makalenin yazılması, Cenk Demirkır: Tahribatlı testlerin gerçekleştirilmesi, makalenin yazılması. Turgay Özdemir: Makalenin yazılması

\section{Kaynaklar}

Anonim (2012), Ulusal deprem stratejisi ve eylem planı 2012-2023 Başbakanlık, Başbakanlık Afet ve Acil Durum Yönetimi Başkanlığı.

Demirkır, C., Çolakoğlu, G., Karacabeyli, E., (2013), The effect of some manufacturing factors on technological properties of plywood from northern Turkey and suitability of the panels for use in shear walls, ASCE Journal of Structural Engineering, 139(12), 04013002,1-6.

EN 338 (2009), Structural timber- Strength classes, Brussels, Belgium.

Gezer, E. D., Temiz, A., Yüksek. T., (2015), Inspection of wooden poles in electrical power distribution networks in Artvin, Turkey, Advances in Materials Science and Engineering, 59818:1-11. DOI:10.1155/2015/659818.

Gezer, E.D., Demirkır, C., Özdemir, T., (2018), Türk Ahşap Konut Örneği "Nemlioğlu Konağı" nın Mekanik Direnç Özellikleri Açısından İncelenmesi. III. International Mediterranean Forest and Environment Symposium, 03-05 October, 2019, Kahramanmaraş, Turkey, 820-825p.

Lee, J.J., Kim, K.C., Bae, M.S., (2003), Patterns of Resistograph for evaluating deteriorated structural wood members, Mockhae Konghak, 31(6), 45-54.

Seavey, R., Larson, T., (2002), Inspection of timber bridges final report, department of wood and paper science university of Minnesota, USA, 1-21s.

TS 2474 Odunun statik eğilmede dayanımının tayini, Türk Standartları Enstitüsü, Ankara.

TS 2478 Odunun statik eğilmede elastiklik modülünün tayini, Türk Standartları Enstitüsü, Ankara.

URL, 1. https://kvmgm.ktb.gov.tr/TR-44799/illere-gore-korunmasi-gerekli-tasinmaz-kulturvarligi-i-.html Erişim tarihi: 06-12-2021.

URL, 2. https://www.fakopp.com/docs/products/withdrawal/withdrawal_guide.pdf Erişim tarihi: 06-12-2021. 